\title{
Phase composition manipulation and twin boundary engineering lead to enhanced thermoelectric performance of $\mathrm{Cu}_{2} \mathrm{SnS}_{3}$
}

Yiqing Weia , Zizhen Zhou ${ }^{\mathrm{a}}$, Pengfei Jiang ${ }^{\mathrm{c}}$, Sikang Zheng ${ }^{\mathrm{a}}$, Qihong Xionga, Bin Zhang ${ }^{\mathrm{b}}$, Guoyu Wang ${ }^{\mathrm{d}}$, Xu Lu ${ }^{\mathrm{a} *}$, Guang Han ${ }^{\mathrm{e} *}$, Xiaoyuan Zhou ${ }^{\mathrm{a}, \mathrm{b} *}$

${ }^{a}$ Center for Quantum Materials \& Devices and College of Physics, Chongqing University, Chongqing 401331, P. R. China

${ }^{b}$ Analytical and Testing Center, Chongqing University, Chongqing 401331, P. R. China

${ }^{c}$ College of Chemical Engineering, Chongqing University, Chongqing 401331, P. R. China

${ }^{d}$ Chongqing Institute of Green and Intelligent Technology, Chinese Academy of Sciences, Chongqing 400714, P. R. China

${ }^{e}$ College of Materials Science and Engineering, Chongqing University, Chongqing 400045, P. R. China

Contact Authors: 1uxu@cqu.edu.cn; guang.han@cqu.edu.cn; xiaoyuan2013@cqu.edu.cn

\section{Section 1: Lattice thermal conductivity $\left(\kappa_{l}\right)$ calculation}

From the single parabolic band (SPB) model based on the Boltzmann transport equation, where the main scattering mechanism of carriers is acoustic phonon scattering, the Lorentz factor $(L)$ can be obtained. The calculation equation is as follows:

$$
\begin{aligned}
L & =\left(\frac{\mathrm{kB}}{e}^{2} *\left(\frac{(r+7 / 2) * F[r+5 / 2, \eta]}{(r+3 / 2) * F[r+1 / 2, \eta]}-\left(\frac{(r+5 / 2) * F[r+3 / 2, \eta]}{(r+3 / 2) * F[r+1 / 2, \eta]}\right){ }^{2}\right) * 10^{\wedge} 8\right. \\
\kappa_{e} & =L \sigma T \\
\kappa_{l} & =\kappa-\kappa_{e}
\end{aligned}
$$




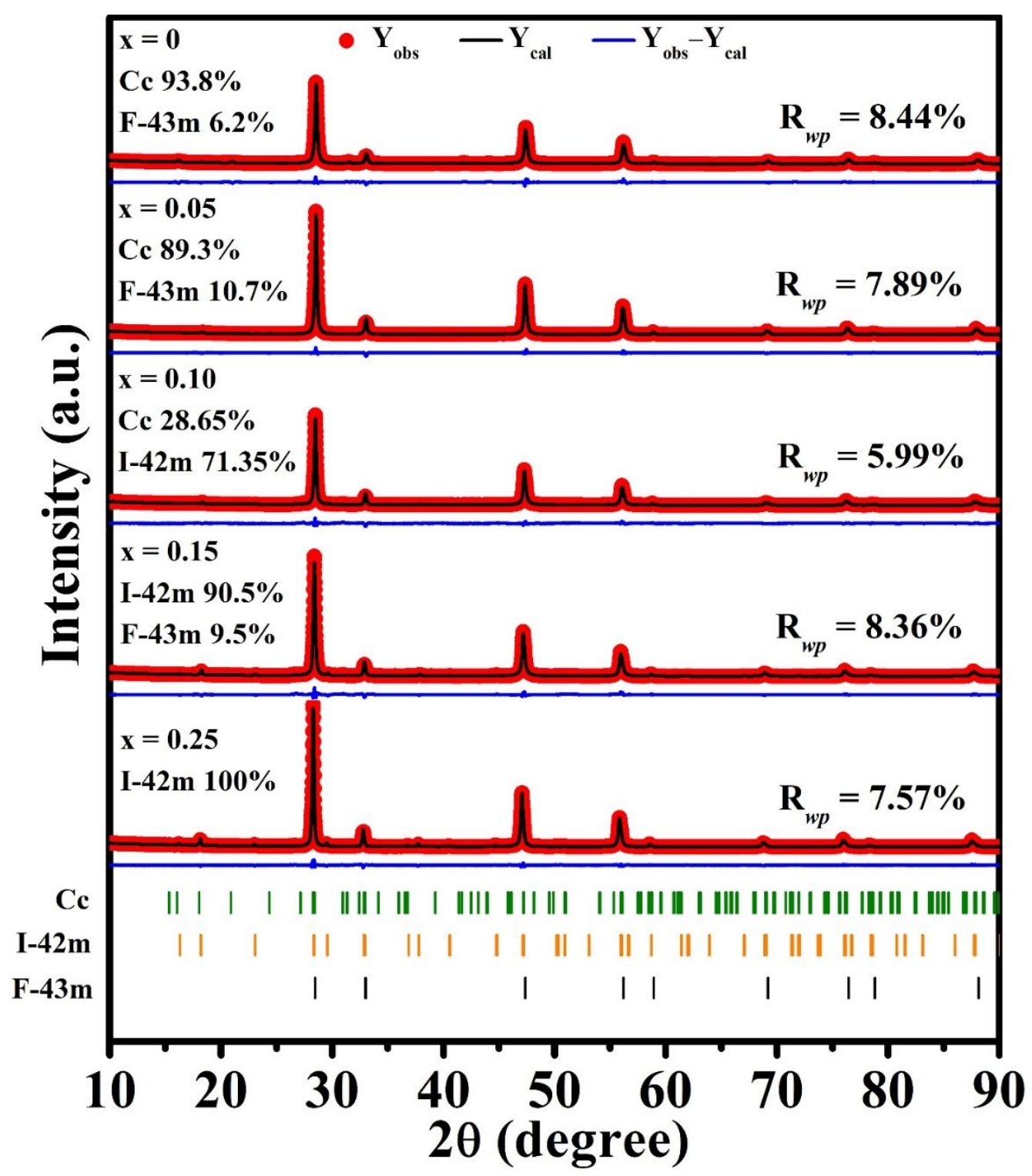

Figure S1. The observed, calculated, and difference Rietveld refined XRD patterns for $\mathrm{Cu}_{2} \mathrm{Sn}_{1-x} \mathrm{In}_{x} \mathrm{~S}_{3}(x=0,0.05,0.1,0.15$ and 0.25$)$ samples.
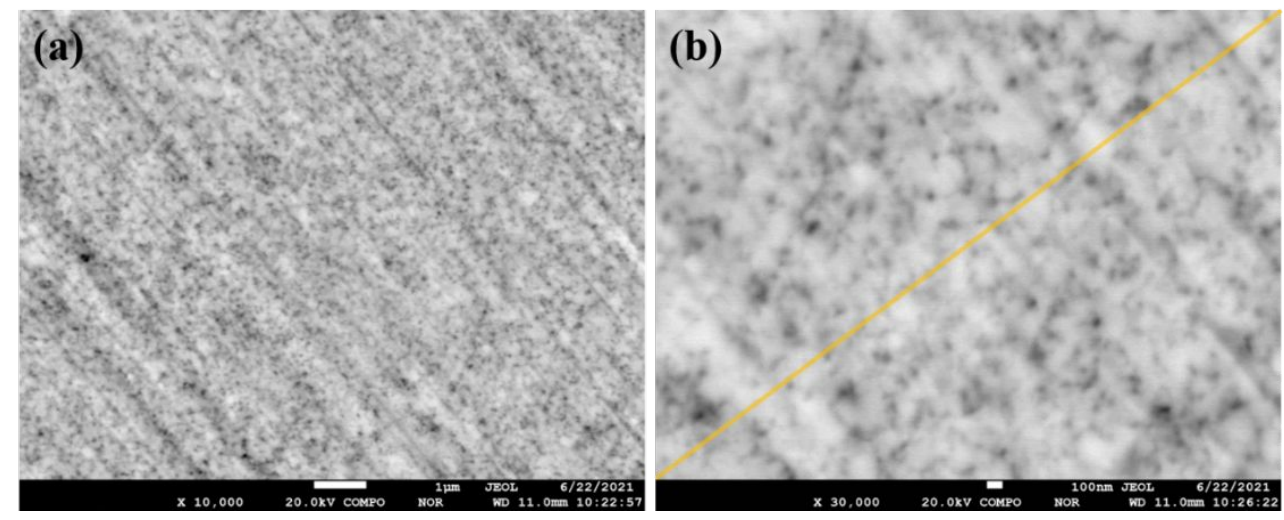

Figure S2. (a, b) SEM images under different magnifications of the $\mathrm{Cu}_{2} \mathrm{Sn}_{0.85} \mathrm{In}_{0.15} \mathrm{~S}_{3}$ sintered sample. 

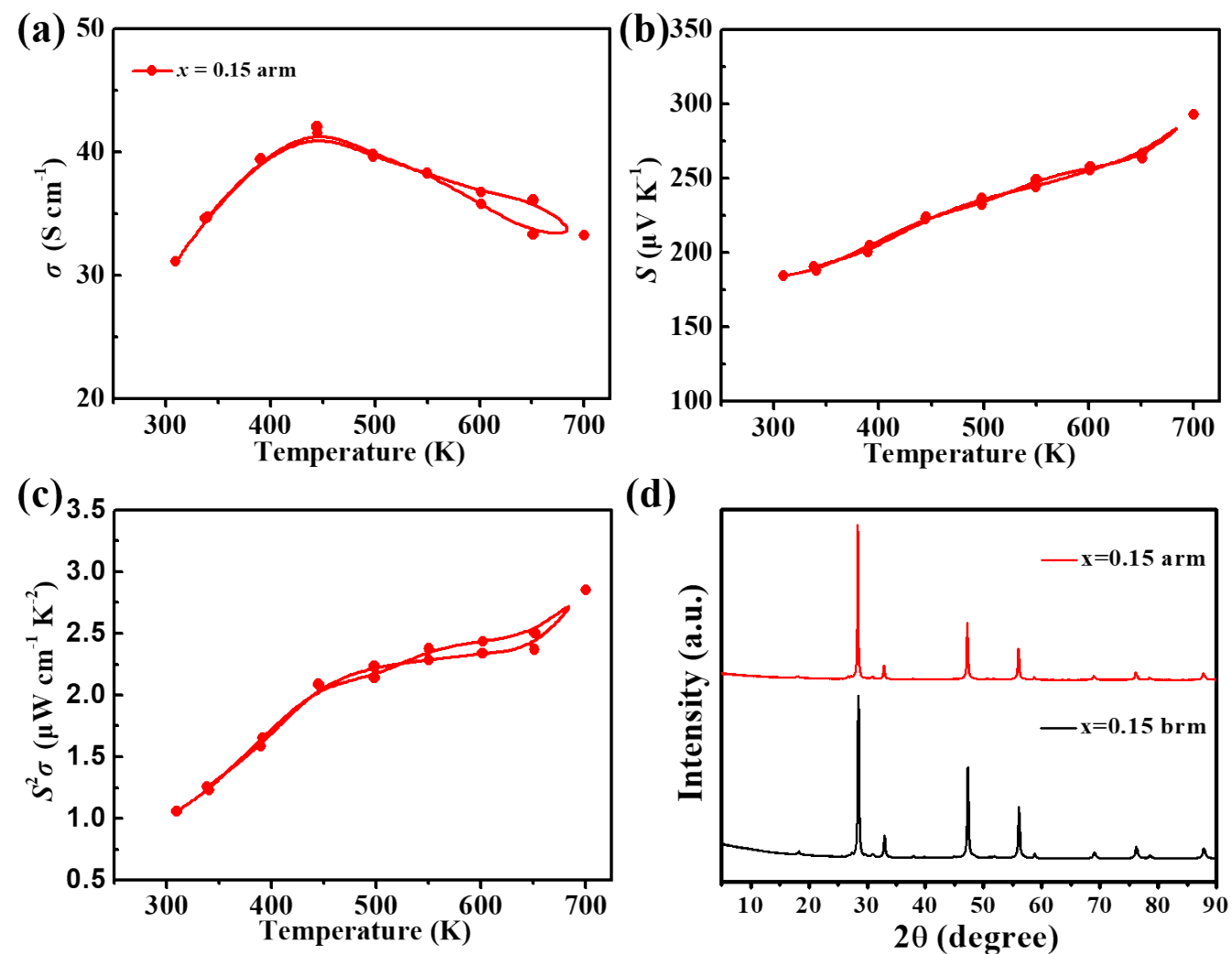

(d)

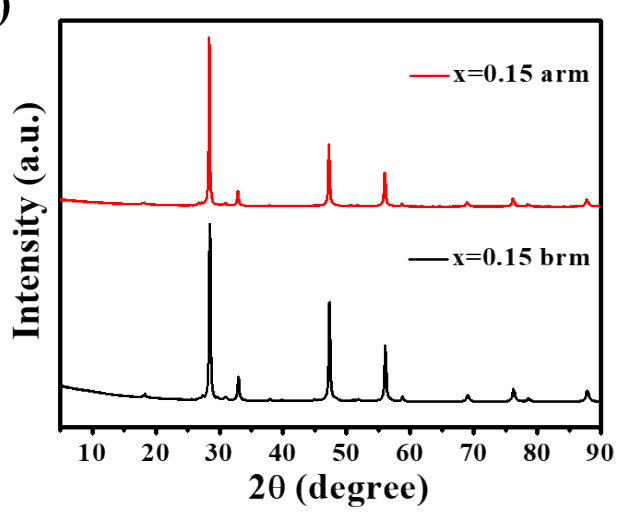

Figure S3. Temperature dependence of (a) electrical conductivity, (b) Seebeck coefficient, (c) power factor of $\mathrm{Cu}_{2} \mathrm{Sn}_{0.85} \mathrm{In}_{0.15} \mathrm{~S}_{3}$ ("brm" stands for before reversible measurement, "arm" stands for after reversible measurement). (d) XRD patterns of $\mathrm{Cu}_{2} \mathrm{Sn}_{0.85} \mathrm{In}_{0.15} \mathrm{~S}_{3}$.

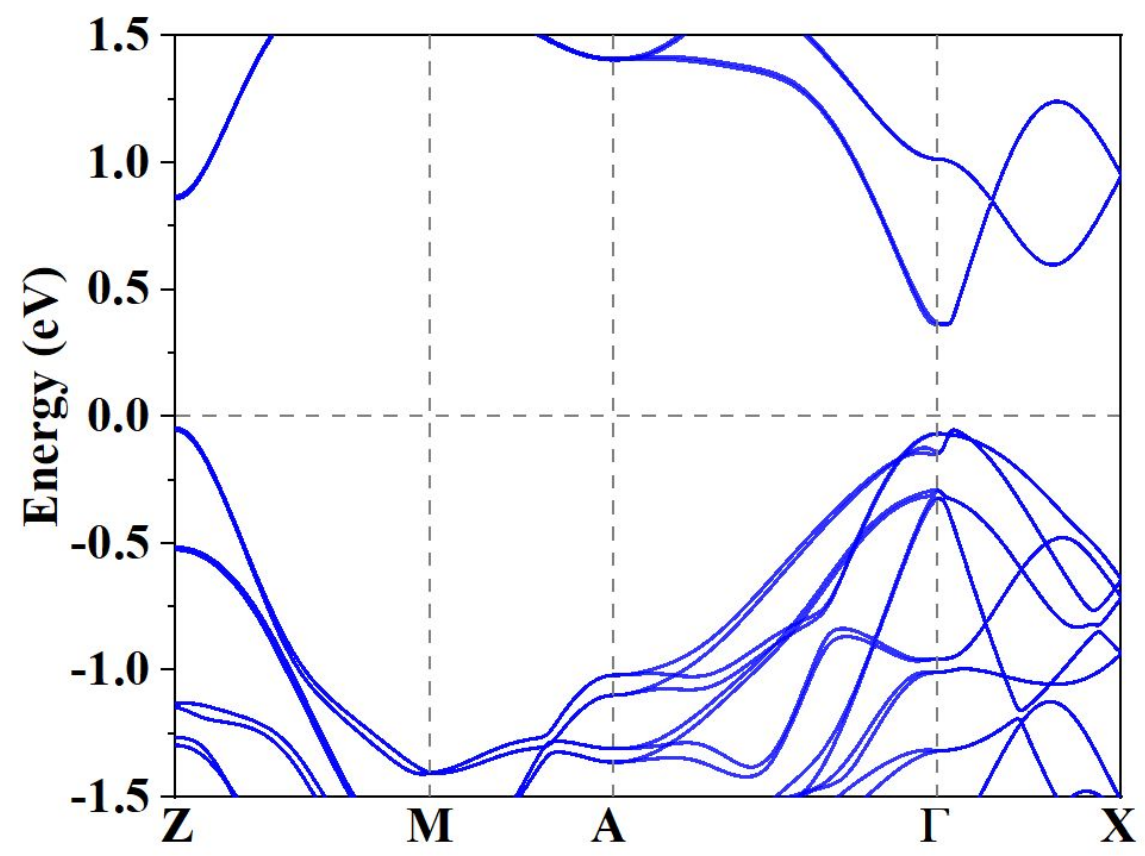


Fig. S4. The calculated band structures of In-doped t-CTS $\left(\mathrm{Cu}_{2} \operatorname{Sn}_{0.75} \operatorname{In}_{0.25} \mathrm{~S}_{3}\right)$. Compared with those of undoped sample, it is found that the band gap of the In-doped sample is slightly reduced and the valance bands are slightly spitted.

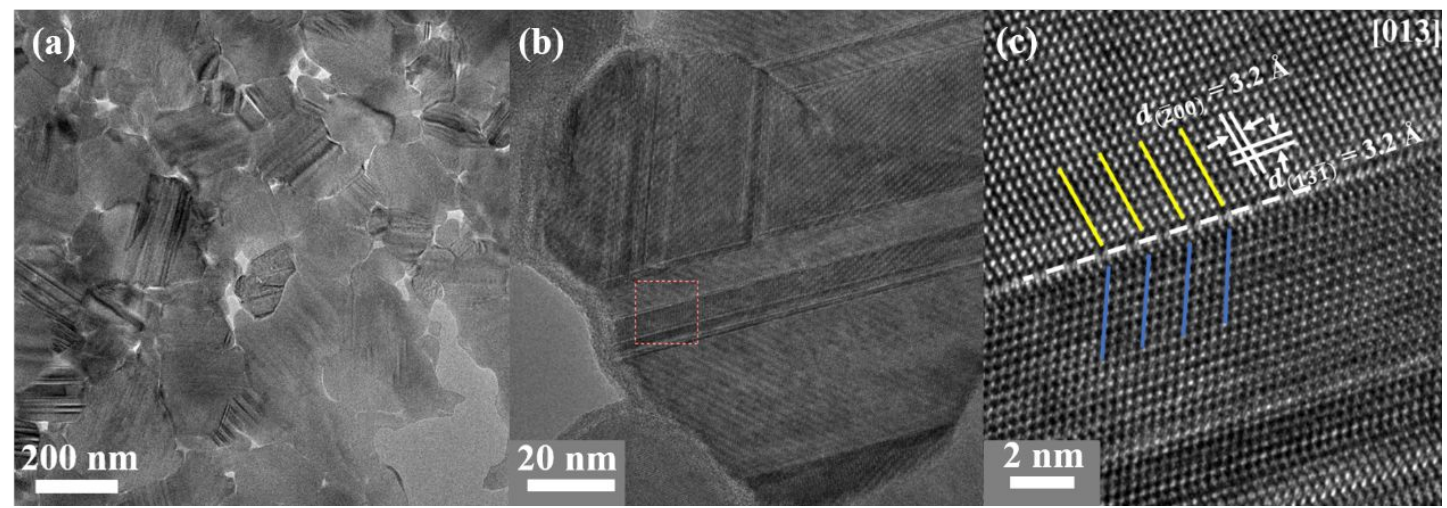

Figure S5. (a) Low-magnification TEM image, (b, c) HRTEM image of $\mathrm{Cu}_{2} \mathrm{SnS}_{3}$.

Table S1. Structural data (position, occupancies, Biso and bond distances) of m-CTS.

\begin{tabular}{|c|c|c|c|c|c|c|}
\hline & $\mathrm{x}$ & $\mathrm{y}$ & $\mathrm{z}$ & occ & B & $\mathrm{d}_{\mathrm{M}-\mathrm{S}}(\AA)$ \\
\hline \multirow{3}{*}{ Sn1 } & \multirow{3}{*}{0} & \multirow{3}{*}{0.08531} & \multirow{3}{*}{0} & \multirow{3}{*}{1} & \multirow{3}{*}{8.03822} & Sn1-S1 2.54 \\
\hline & & & & & & $\mathrm{Sn} 1-\mathrm{S} 22.25$ \\
\hline & & & & & & Sn1-S3 2.46 \\
\hline \multirow{3}{*}{$\mathrm{Cu} 1$} & \multirow{3}{*}{0.01052} & \multirow{3}{*}{0.41562} & \multirow{3}{*}{-0.00842} & \multirow{3}{*}{1} & \multirow{3}{*}{0.32221} & Cu1-S1 2.41 \\
\hline & & & & & & $\mathrm{Cu} 1-\mathrm{S} 22.23$ \\
\hline & & & & & & Cu1-S3 2.16 \\
\hline \multirow{3}{*}{$\mathrm{Cu} 2$} & \multirow{3}{*}{-0.00001} & \multirow{3}{*}{0.25519} & \multirow{3}{*}{0.49559} & \multirow{3}{*}{1} & \multirow{3}{*}{0.32221} & $\mathrm{Cu} 2-\mathrm{S} 12.14$ \\
\hline & & & & & & $\mathrm{Cu} 2-\mathrm{S} 22.26$ \\
\hline & & & & & & $\mathrm{Cu} 2-\mathrm{S} 32.35$ \\
\hline S1 & 0.40345 & 0.09163 & 0.12114 & 1 & 1.42100 & \\
\hline S2 & 0.35484 & 0.22248 & 0.62192 & 1 & 1.42100 & \\
\hline S3 & 0.35398 & 0.40832 & 0.10563 & 1 & 1.42100 & \\
\hline
\end{tabular}

Table S2. Structural data (position, occupancies, Biso and bond distances) of c-CTS.

\begin{tabular}{cccccc}
\hline \hline $\mathrm{x}$ & $\mathrm{y}$ & $\mathrm{z}$ & occ & $\mathrm{B}$ & $\mathrm{d}_{\mathrm{M}-\mathrm{S}}(\AA)$ \\
\hline
\end{tabular}




\begin{tabular}{lllllll}
\hline Sn1 & 0 & 0 & 0 & 0.3333 & 1.29025 & 2.34 \\
Cu1 & 0 & 0 & 0 & 0.6667 & 1.29025 & 2.34 \\
S1 & 0.25 & 0.25 & 0.25 & 1 & 0.72506 & \\
\hline
\end{tabular}

Table S3. Structural data (position, occupancies, Biso and bond distances) of t-CTS.

\begin{tabular}{|c|c|c|c|c|c|c|}
\hline & $\mathrm{x}$ & $\mathrm{y}$ & $\mathrm{z}$ & occ & B & $\mathrm{d}_{\mathrm{M}-\mathrm{S}}(\AA)$ \\
\hline $\operatorname{Sn} 1$ & 0 & 0.5 & 0.25 & $\begin{array}{l}\text { P1 } \\
0.30821\end{array}$ & 3.19435 & 2.422 \\
\hline $\mathrm{Cul}$ & 0 & 0.5 & 0.25 & $\begin{array}{l}\text { P2 } \\
0.54774\end{array}$ & 3.19435 & 2.422 \\
\hline $\mathrm{Sn} 2$ & 0 & 0 & 0.5 & $1-2 * \mathrm{P} 1$ & 1.78268 & 2.386 \\
\hline $\mathrm{Cu} 2$ & 0 & 0 & 0.5 & $1.5-2 * \mathrm{P} 2$ & 1.78268 & 2.386 \\
\hline $\mathrm{Cu} 3$ & 0 & 0 & 0 & 0.5 & 1.11688 & 2.231 \\
\hline S1 & 0.23802 & 0.23802 & 0.11613 & 0.375 & 1.20474 & \\
\hline
\end{tabular}

Table S4. The room temperature carrier concentration of $\mathrm{Cu}_{2} \mathrm{Sn}_{1-x} \mathrm{In}_{x} \mathrm{~S}_{3}(x=0,0.05$, $0.1,0.15$ and 0.25$)$ samples.

\begin{tabular}{cccccc}
\hline \hline & $x=0$ & $x=0.05$ & $x=0.10$ & $x=0.15$ & $x=0.25$ \\
\hline $\mathrm{n}\left(* 10^{19}\right)$ & 0.24 & 1.5 & 4.8 & 12 & 13 \\
\hline
\end{tabular}

It can be seen that the carrier concentration is enlarged with increasing In content $(x$ $=0,0.05,0.1,0.15)$. To separate the contributions of elevated carrier concentration and phase transition to the electronic properties, the "material quality factor B" is evaluated. After the In doping amount is changed from $x=0.05$ to a higher composition, the $\mathrm{B}$ factor increases from 0.0040 to 0.014 , which indicates that the intrinsic thermoelectric potential has been improved. Such increase is due to tetragonal phase rather than by doping effect. 